British Journal of Psychiatry (1990), 157, 773-785

\title{
Correspondence
}

Editor: Ian Pullen

Contents: Insight and psychosis/The 'new crosscultural psychiatry'/Progesterone prophylaxis?/ Benzodiazepine withdrawal/ECT in neuroleptic malignant syndrome/Was Hitler a Christian?/The musical idiot savant/Anorexia nervosa and OCD/ Toad-lickers psychosis - a warning/Self-catering during rehabilitation/A Freudian lacuna?/Genetic origins of psychosis/Post-traumatic stress disorder/ Malaria presenting as atypical depression/Anorexia nervosa in people of Asian extraction/Temporal lobe in schizophrenia

\section{Insight and psychosis}

SIR: David's comments on 'Insight and psychosis' (Journal, June 1990, 156, 798-808), and those of other authors quoted by him, that "a surprising proportion of patients do possess insight", fully confirm my own experience.

In an essentially community-orientated adult psychiatric service, clinicians such as myself rely more than has traditionally been the case on patients assuming a considerable degree of responsibility for their illness and its treatment, and indeed for their general behaviour in a public context. It has been necessary, and increasingly a delightful surprise, to discuss fully with those we call 'long-term mentally ill' what Dr David has called their insight.

I have found that patients' comments are often at first misleading. One man in his fifties recently told me that he was definitely not mentally ill and did not require medication. This was our first meeting and he mistrusted me. Later, however, it transpired that he knew very well he had been suffering symptoms of schizophrenia much earlier in life and that depot neuroleptic medication controlled these symptoms more or less completely. He was anxious, however, that this admission would result in the removal of his Home Office Warrant, and that he would thereby lose his benefits and be forced to seek employment.

I was able to reassure this man that he would continue to receive benefits and could continue to attend the industrial workshop as before. The example demonstrates a further advantage for the clinician in exploring fully with the patient his or her insight. The therapeutic relationship deepens. Above all I have found in a number of cases that a patient's self-esteem rises spontaneously and almost palpably when their own grasp of their illness, often astonishingly sophisticated, is given professional credence.

May I therefore endorse Dr David's conclusions. May I suggest that psychiatrists do not wait for the results of formal research, and that they undertake informal research of their own with the very next long-term mentally ill patient they encounter. Too convincingly, I believe, have we been trained to attempt the imposition of our expectations on our patients, and we do so without recognising the burden, the awkwardness, the mistrust it places upon ourselves. Letting patients speak for themselves and take responsibility for themselves is a very liberating experience.

Finally, I wonder that Dr David omitted from his Appendix questions designed to clarify whether insight into another's illness might be preserved despite the loss of personal insight. Perhaps the publication in preparation (The Assessment of Insight by A. S. David \& G. Nestadt) will put this right.

L. D. CUlliford

Aldrington House

Hove Community Mental Health Centre

35 New Church Road

Hove BN3 4AG

SIR:-David's thought-provoking article (Journal, June 1990, 156, 798-808) seems to raise as many questions as it answers. My unease about it is due to the extent to which he assumes observer uniformity when assessing psychotic patients. He limits his use of the term 'insight' to the subject's appraisal of his mental state and his ability to label certain mental phenomena as morbid - "it simply requires the acceptance of personal illness affecting the mental apparatus". This seems fine at face value and even if the term 'illness' is dropped and 'change' used it still ignores the observer.

Alas, psychiatrists working in everyday practice are not as objective as we would like to think. Kreitman et al (1961) has shown that inter-rater 